\title{
The international trade position of Argentina. Towards a process of export diversification?
}

\author{
Marta Bekerman and Federico Dulcich
}

ABSTRACT

\begin{abstract}
This study analyses how far the strong expansion of Argentine exports since 2003 has been due simply to favourable external conditions and how industrial manufactures have behaved. It finds that the country's pattern of international specialization has not greatly altered at the major category level, but that both primary products and manufactures of agricultural origin, which account for much of the trade surplus, have undergone significant changes in composition. In addition, regional trade has consolidated and traditional partners such as the European Union and the United States have been displaced to some extent by China. Industrial manufactures have continued to suffer from a strong comparative disadvantage, but certain high-technology industrial sectors, such as agricultural machinery and pumps and compressors, have started to become competitive, while seamless oil and gas tubing is already highly competitive.
\end{abstract} products, competitiveness, trade statistics, Argentina of Economic Sciences of the University of Buenos Aires and lead researcher at the National Council of Scientific and Technical Research (CONICET).marbekerman@gmail.com

Federico Dulcich is a researcher with the Centre for the Study of Economic Structures (cenes) at the Faculty of Economic Sciences of the University of Buenos Aires and a research fellow at the National Council of Scientific and Technical Research (CONICET). federicomd2001@yahoo.com.ar 


\section{I}

\section{Introduction}

In the period following the end of the convertibility regime, Argentina displayed high levels of growth while maintaining a positive trade balance. This made it possible to implement a debt service policy that sharply reduced the level of external debt relative to output, giving the trade balance a very important role in determining the currentaccount balance. This made it important to consolidate a pattern of international trade that would ensure steady growth untrammelled by external constraints.

A country's international trade specialization profile is critical to its economic structure. The opportunity to develop sectors with high value added can mean higher wages and larger surpluses that make it possible for the public sector to implement income redistribution policies, with better health and education services. Accordingly, a thorough debate about recent trends in Argentina's specialization pattern is essential.

The country's exports have grown strongly since 2003. What accounts for this situation, which seems to have neutralized the external constraint, at least for now? To what extent can it be put down purely to favourable external conditions? What impact have these external conditions had on the overall specialization pattern of the
Argentine economy, and particularly on the behaviour of industrial manufactures? Is it possible to identify continuities and discontinuities within this pattern? The present study will seek to answer these questions.

It will begin with a brief exposition of the concept of the specialization pattern, its theoretical importance and its history (section II). It will then present the main changes in the macroeconomic context over the past decade (section III) before analysing the evolution of revealed comparative advantage for the country's different production categories and main trading partners, while also taking account of the role played by the improving terms of trade (section IV). Section V will analyse the behaviour of manufactures of industrial origin (MIO) by tracking the evolution of revealed comparative advantage, positing a situation of balance in industrial trade for this classification in order to ascertain the relative changes undergone by the different MIO sectors. It will then analyse international MIO trade results in terms of the sector's technology content and the gap separating it from the technical processes of the international frontier (section VI). Lastly, the conclusions of the study will be presented (section VII).

\section{II}

\section{The specialization pattern and its theoretical importance}

The international division of labour and the consolidation of capitalism as a social form of production around the globe opened up a theoretical debate about the specialization of the different nations within the nascent global market and the role played by this market in the levels of well-being enjoyed by individuals. This concept has been addressed by different schools of thought that have set out to study it either from an analytical perspective or with reference to the controversial policy implications that can be drawn from its analysis.

Departing from the neoclassical stance based on the Heckscher-Ohlin model (Appleyard and Field, 1997), a variety of alternative theoretical approaches emerged, emphasizing new sources of comparative advantage and stressing the relevance of the specialization pattern for a nation's growth path.

New international trade theory, endogenous growth theory and different neo-Schumpeterian schools of thought have variously laid the stress on scale economy issues, the existence of reproducible factors with non-decreasing returns (essentially what they term human capital), spillover effects between industries and international differences in knowledge and technological capabilities (Bekerman and Sirlin, 1999). 
On the basis of this conception of a country's international trade position, which ascribes a dynamic character to comparative advantage, there has arisen a more recent literature advancing different arguments that emphasize the importance of export diversification. In the first place, such diversification helps to reduce the volatility of export currency earnings, and thence of growth in the economy (Agosin, 2009). This is particularly important for developing countries, which tend to have little access to the international financial market when they need to cover temporary current-account deficits, and which usually depend heavily on imported capital goods and inputs.

At the same time, export diversification entails a productive diversification that enables local agents to "discover" unexplored comparative advantage in their economy, with export pioneers showing the way to those who come after them (Hausmann and Rodrik, 2003). Countries that have a high-quality export basket based on more sophisticated items enjoy higher subsequent growth than countries that do not (Rodrik, 2005). In this context, it is very important for the migration of producers to new sectors not to be blocked by high barriers to entry (patents, large efficient minimum scales, etc.). These productive diversification processes generate a range of externalities (rising productivity because of agents' productive specialization, increasing workforce skills, etc.) that positively impact growth. This has led some authors to defend the role of the State in "guiding the market" towards the discovery of new capabilities (Wade, 1989).

To sum up, there is a broad consensus that a country's specialization pattern is crucial to its economic structure and thence to the sustainability and level of long-term growth in the economy. Within this context, the different sectors will have different levels of technological spillovers and differing potential to capture exceptional earnings by differentiating processes or products and thence accumulate capital and generate subsequent increases in productivity. This divergent evolution of productivity will influence their scope to raise real wages and generate larger surpluses that enable the public sector to implement income redistribution policies.

The following sections will analyse the macroeconomic context and the evolution of specialization patterns in the Argentine economy in the last decade.

\section{III}

\section{The macroeconomic context}

The collapse of the convertibility system, which entailed devaluation of the real exchange rate, led to a crucial transformation in the macroeconomic policy of Argentina. The initial period of uncertainty and shrinking domestic demand was followed, once the 2001-2002 crisis was over, by a process of economic recovery that made it possible to inaugurate a stage of steady growth without undermining the trade balance.

This was because the recovery process was based not only on reviving domestic demand but also on a strong expansion of exports and a process of import substitution. Thus, what may perhaps be considered a very striking macroeconomic feature of the post-convertibility period is the lifting of the external constraint on growth. The economy grew at high rates for eight years running (with a single interruption in 2009) even as a substantial trade surplus was maintained (see figure 1).

From 2001 there was a structural shift in the composition of final demand, with the shares of exports and investment increasing at the expense of public- and private-sector consumption. External sales rose from the equivalent of $9.3 \%$ of aggregate demand during 19951997 to $21.7 \%$ between 2003 and 2005, a share that then drifted back down as public-sector consumption, and especially investment, recovered. ${ }^{1}$

Katz and Bernat explain that changes in macroeconomic regimes initiated during downturns, as happened in Argentina in late 2001, give rise to these shifts in the composition of aggregate demand because they affect the various sectors differently, depending on how far they lag the technical processes of the production frontier. Those closest to the international technical frontier can direct their surpluses to the external market when domestic consumption falls. Conversely, less productive sectors

\footnotetext{
1 Investment represented $10.4 \%$ of aggregate demand in 2002 and now represents $19 \%$.
} 
FIGURE 1

Argentina: GDP and external trade flows, 1998-2010

(Millions of current dollars)

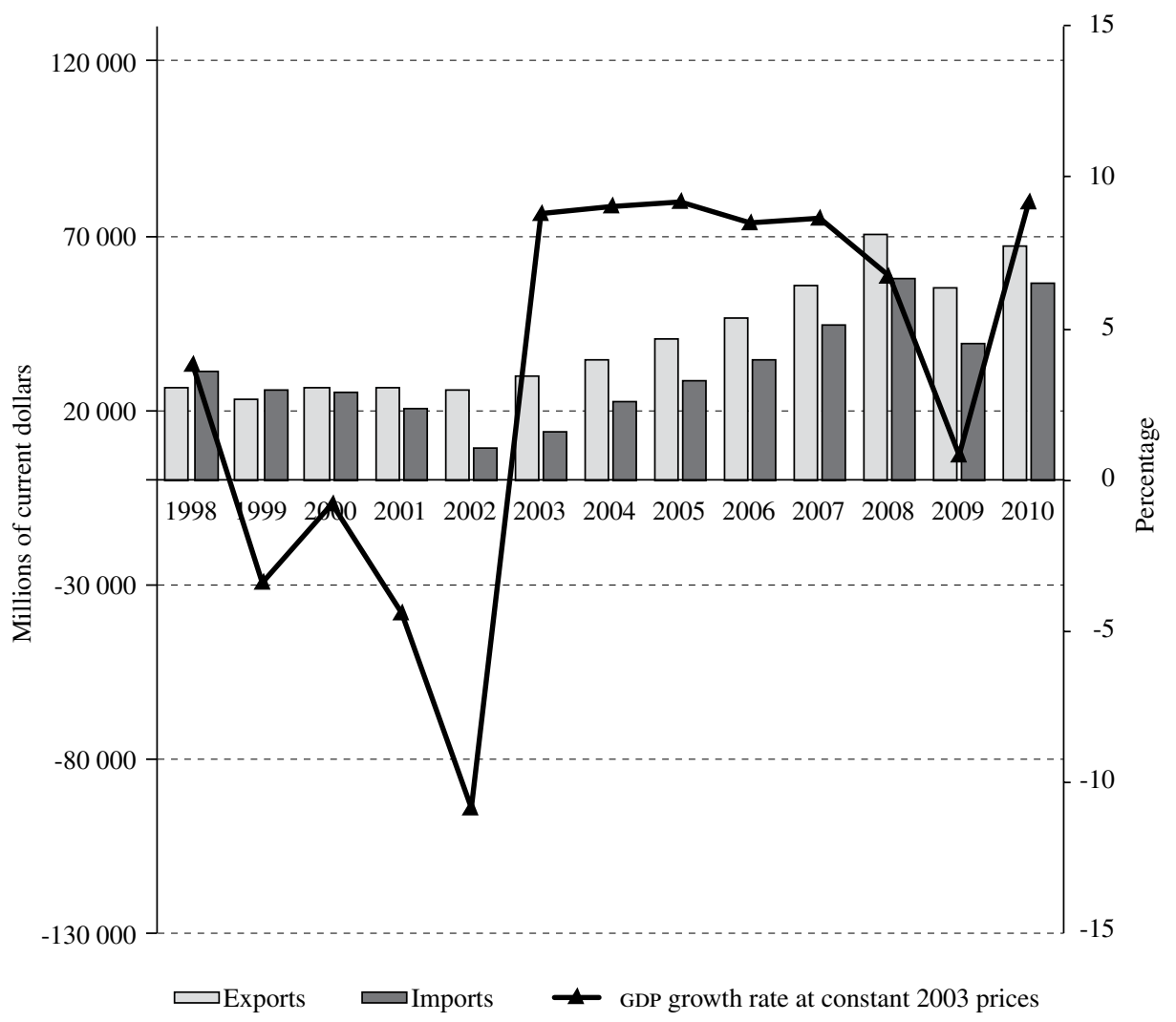

Source: prepared by the authors on the basis of National Institute of Statistics and Censuses (INDEC) and United Nations Commodity Trade Statistics Database (COMTRADE).

GDP: gross domestic product.

cannot compete internationally and are more affected by the recession, with greater exit by firms (Katz and Bernat, 2011). One result of this process should be an increase in export potential, and this helps to explain why Argentina's external trade position came to play a much more important role as a driver of aggregate demand than in the previous decade. It also indicates, however, that these circumstances did not affect all industrial sectors alike. Their responses were influenced by different factors, especially the levels of competitiveness they presented before the crisis. It is thus important to observe what transformations occurred in the international trade position of the major production categories and industry sectors, something that will be dealt with in the following sections. 


\section{IV \\ The external trade position by major production categories and main trading partners}

\section{Methodological issues}

(a) The revealed comparative advantage ( $R C A)$ index ${ }^{2}$

To determine an economy's specialization pattern, exports and imports must be studied simultaneously, and the sectoral trade balance is accordingly taken as a variable of analysis. However, trade balances must be normalized to discount the effect of temporary factors (especially macroeconomic ones) that result in overall trade surpluses or deficits.

In view of this, the RCA indicator has been used to analyse the overall specialization pattern, so that:

$$
\begin{gathered}
R C A_{i}=\left[\left(X_{i}-M_{i}\right)-(X-M) *\left(X_{i}+M_{i}\right) /(X+M)\right] \\
* 1000 /(X+M)
\end{gathered}
$$

where $\left(X_{i}-M_{i}\right)$ is the trade balance observed in sector $i$, and $(X-M) *\left(X_{i}+M_{i}\right) /(X+M)$ is a notional value representing the sectoral component of $i$ in the overall surplus or deficit.

Revealed comparative advantages thus represent normalized sectoral trade balances, corresponding to a hypothetical situation of balanced trade. Accordingly, they are an indicator of the nation's comparative advantages.

As can be appreciated from the indicator, the way the observed sectoral balances are "normalized" is by deducting from them a notional sectoral component estimated from the sector's share of total trade (exports plus imports).

This method entails some simplifying assumptions, such as that temporary imbalances originating in macroeconomic variables affect all sectors alike (or, more precisely, affect them strictly in proportion to their share of total trade). Evolving activity levels can influence the evolution of the RCA indicator by their dissimilar impact on the behaviour of imports and exports. ${ }^{3}$

\footnotetext{
2 This index is based on the one developed by Miotti, Quenan and Winograd (1998).

3 A higher level of activity may create greater import pressure from sectors with higher levels of import elasticity relative to output. Conversely, a recessionary situation will produce the opposite effect, as can be seen in the evolution of the index by major production categories for 1999-2002.
}

\begin{abstract}
Although the RCA indicator is suitable for analysing the specialization pattern overall, it can create large biases for trade by destination. The greater the differences in the ratios between the trade balance and total trade for each destination, on the one hand, and for the whole world, on the other, the larger these biases will be. Theoretically, an analysis of trading activity that assumes balanced trade should be much more relevant to worldwide trade than to bilateral trade situations, where there may be no economic forces pushing trade back towards balance, at least in the short run. Ultimately, analysing trade by destination brings in a new issue, trade triangulation, which cannot be captured by the RCA indicator.
\end{abstract}

\section{(b) The trade performance (TP) index}

In view of these problems, a slightly different indicator has been used to study bilateral trade with Argentina's various partners. We have called this the normalized trade performance index, or simply the trade performance (TP) index:

$$
\begin{gathered}
T P_{i j}=\left[\left(X_{i j}-M_{i j}\right)-\left(X_{i j}+M_{i j}\right) *(X-M) /(X+M)\right] \\
* 1000 /(X+M)_{j}
\end{gathered}
$$

where subscript $i$ represents each of the sectors and subscript $j$ each trading partner, while no subscript means that total exports and imports are meant.

The difference from the RCA indicator (used to analyse the overall specialization pattern) is that in this case the overall trade balance is still used to normalize the sectoral trade balance (calculate the notional value), whereas bilateral trade variables are used for the rest of the indicator. In other words, these are trade situations corresponding to a state in which overall (and not bilateral) trade is balanced. This means that the sum total of the values for all sectors (which we shall call the total trade performance) of this indicator for each destination will no longer be zero. A negative (positive) sign will indicate that there is a larger (smaller) trade deficit or a smaller (larger) trade surplus with a particular country (relative to its total trade share) than with the remaining countries. A negative figure which increases over a period could be the consequence of a deterioration in particular sectors that is not offset by the behaviour of others. 
The trade performance indicator thus presents differences from the RCA indicator. The essence of the comparative advantage concept is the interrelationship between sectors, which means that the advantages of some are matched by the disadvantages of others. In this case, trade with a particular country may evince a positive or negative performance for all sectors. Total bilateral trade is taken as the final denominator for this indicator to avoid the effects arising from the differing shares of the various countries in Argentina's total trade and to make the values for trade with different trading partners and for worldwide trade comparable.

\section{(c) The MIO revealed comparative advantage $\left(R C A_{M I O}\right)$ index}

The fact that Argentina specializes heavily in primary products and manufactures of agricultural origin (MAO) means that RCA levels are strongly negative for sectors producing manufactures of industrial origin (MIO) and makes variations in them insignificant. Accordingly, a revealed comparative advantage index has been prepared for the different MIO sectors, relating them to the average for the universe of this category used in section V. The $\mathrm{RCA}_{\mathrm{MIO}}$ index is calculated as follows:

$$
\begin{gathered}
R C A_{M I O i}=\left[\left(X_{i}-M_{i}\right)-\left(X_{M I O}-M_{M I O}\right) *\right. \\
\left.\left(X_{i}+M_{i}\right) /\left(X_{M I O}+M_{M I O}\right)\right] * 1000 /\left(X_{M I O}+M_{M I O}\right)
\end{gathered}
$$

where $\left(X_{i}-M_{i}\right)$ is the trade balance in sector $i$ (which must be an MIO sector) and $\left(X_{M I O}-M_{M I O}\right) *\left(X_{i}+M_{i}\right) /$ $\left(X_{M I O}+M_{M I O}\right)$ is a notional value representing the sectoral component of $i$ in the MIO surplus or deficit.

Structurally, this index is analogous to the RCA index, except that the overall surplus or deficit is replaced by the MIO surplus or deficit. Consequently, it represents a normalization of the trade balance in the different MIO sectors, assuming total MIO trade to be in balance. It is important to note that there are no economic tendencies in Argentina towards balance in MIO trade, as there are in the case of overall trade. However, the index does serve to express the performance of a sector in relation to the overall behaviour of the MIO category. To do this, it compares the actual trade balance with the notional trade balance for the sector concerned. The latter is prepared by taking the sector's share of MIO trade (both imports and exports) and of the total trade balance of this category. A positive (negative) $\mathrm{RCA}_{\mathrm{MIO}}$ index value implies that the actual balance of the sector is larger (smaller) than the notional balance, and so the actual trade surplus is larger (smaller) than the notional surplus (when MIO are in surplus overall) or the trade deficit is smaller (larger) than the notional one (when MIO are in deficit overall). Consequently, the sum of all MIO sectors of the index is nil.

\section{The behaviour of RCA in the last decade. Analysis by major categories}

Historically, the Argentine economy has had a dual pattern of specialization. Its sources of comparative advantage lie in the production of primary products and MAO, while it presents strong comparative disadvantage in MIO. Under convertibility, this pattern of specialization was accentuated by the growing appreciation of the real exchange rate. During that period, the comparative advantage of primary products increased because of the performance of cereals and oilseeds and, to a lesser extent, unprocessed fish and seafood (Bekerman and Cerdeiro, 2007). Within the MAO category, animal feed, oils and fats were the bestperforming sector, followed by hides and meat. It might be said that the food and beverages sector consolidated its external competitive hegemony and its position within the Argentine industrial structure, and its lesser elasticity relative to domestic activity meant that it was less affected than other industry sectors during the 1998-2002 crisis.

When the behaviour of MIO during the convertibility period is analysed, sectors can be divided into two groups. In the industrial commodities category, the privatization of public-sector enterprises resulted in consolidation of certain private-sector business groups that increased their market power and were able to move towards technological convergence with the international frontier. The clearest example of this is the production of seamless tubes for oil extraction. Conversely, the machinery, electronic appliances and transport equipment sectors had a large competitiveness deficit, and this widened in the late 1990s in the face of world technological progress and failure to bring on local innovation activities (Bekerman and Sirlin, 1999).

The evolution of the RCA index during the first decade of this century can be seen in figure 2 . In the aggregate, Argentina's overall pattern of international specialization has not changed substantially. It retains a clear competitive advantage in primary products and has been increasing this advantage in MAO. In the case of primary products, this advantage progressively consolidated as technical processes from the international frontier, such as the use of genetically modified (GM) and no-till crops, were introduced into the country. In the case of MAO, growth is being seen in sectors that benefit from the differential in export duties between their input (grains or oilseeds) and their final output (oils and milling by-products). These windfall earnings come on top of those attributable to leading-edge technical processes and rely on the ability 
Argentina: RCA index by major production categories, 1998-2010 (Absolute value index)*

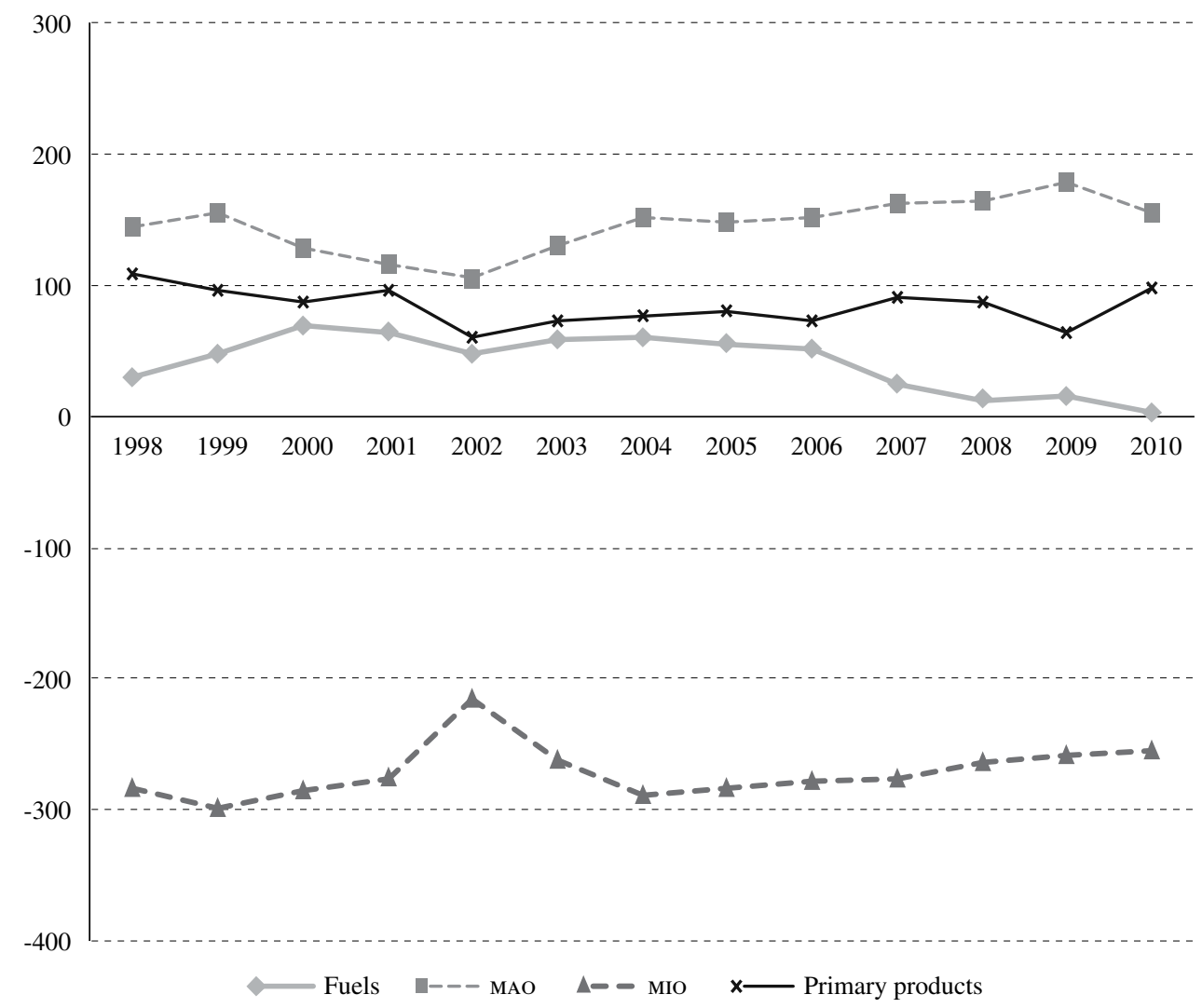

Source: prepared by the authors on the basis of National Institute of Statistics and Censuses (INDEC) and United Nations Commodity Trade Statistics Database (COMTRADE).

* Figures calculated from the equations described in section IV of this article.

RCA: revealed comparative advantage.

MAO: manufactures of agricultural origin.

MIO: manufactures of industrial origin.

of the primary sector to transfer some of the yields from land via the export duties system implemented after the currency was devalued in 2001-2002.

In the case of fuels, conversely, there has been a downward trend in recent years. This is explained by the strong growth of oil imports (from US\$ 198 million in 2003 to US\$ 2.567 billion in 2010), which led to a drop of 59\% in net exports (US\$ 1.608 billion in 2010). Driven by economic expansion, domestic demand grew by substantially more than output, and this negatively affected the trade position of the sector.
MIO continue to be affected by strong comparative disadvantages, but these have tended to ease slightly in recent years.

The obvious correlation between the MIO deficit and the activity level is due to the large share of MIO manufactures accounted for by certain categories associated with the workings of the economy, such as capital goods, inputs and parts and components. ${ }^{4}$ This meant that the deficit rose during the economic recovery period and fell in 2009 owing to the impact of the international crisis on the domestic activity level (see figure 3 ).

4 These categories account for $80 \%$ of mio imports, a structural share that was constant throughout the decade. 
FIGURE 3

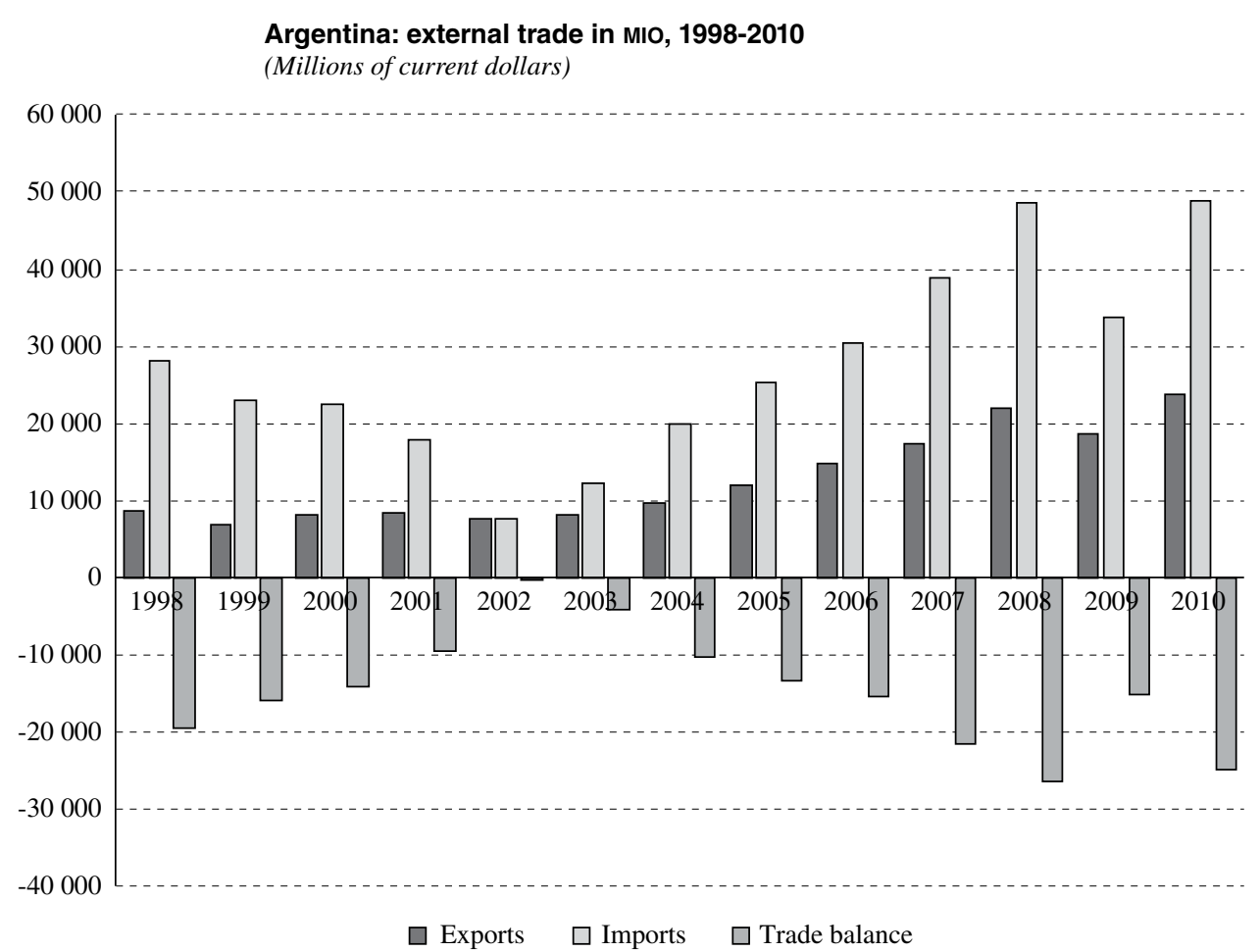

Source: prepared by the authors on the basis of National Institute of Statistics and Censuses (INDEC) and United Nations Commodity Trade Statistics Database (COMTRADE).

MIO: manufactures of industrial origin.

\section{The impact of the terms of trade}

The substantial MIO trade deficit has been more than offset during the last five years by a large surplus in primary products and MAO, with an overall trade surplus the result. A key factor behind this surplus has been the improvement in the terms of trade driven by the sharp rise in demand for food products, particularly in Asian markets.

What would have happened to the Argentine trade balance if international prices had held steady at 2003 levels? If the effect of changes in these prices is discounted ${ }^{5}$ (by taking constant 2003 prices), it can be seen that there would still be a trade surplus, but of only US\$ 2.5 billion, i.e., it would be much smaller than those recorded in recent years (about US\$ 13 billion). This is because the hypothetical surpluses for primary products and MAO would be much lower than

5 See point 1 of annex II for methodological details of the conversion to constant 2003 prices. those actually achieved at current prices (see figure 4). Consequently, today's large trade surplus is heavily dependent on relative price movements, something that reveals a certain fragility in the country's international trade pattern should the international crisis worsen. In addition, the trade balance is the main provider of currency for the current account, as the country has a structural deficit in the services category, albeit one that has been declining in recent years.

Nonetheless, it is important to stress that the Argentine trade balance would have been in surplus in what was a period of strong growth, even after discounting the favourable evolution of international relative prices since 2003, and this represents a change from the past. ${ }^{6}$

\footnotetext{
6 It is important to note that other general equilibrium effects on this evolution of the trade balance (investment, impact of the activity level on imports, etc.) are not considered, and only the price effect is analysed (although this was very significant for the period). To consider all effects in combination within a general equilibrium model would require a special analysis that is beyond the scope of this study.
} 
FIGURE 4

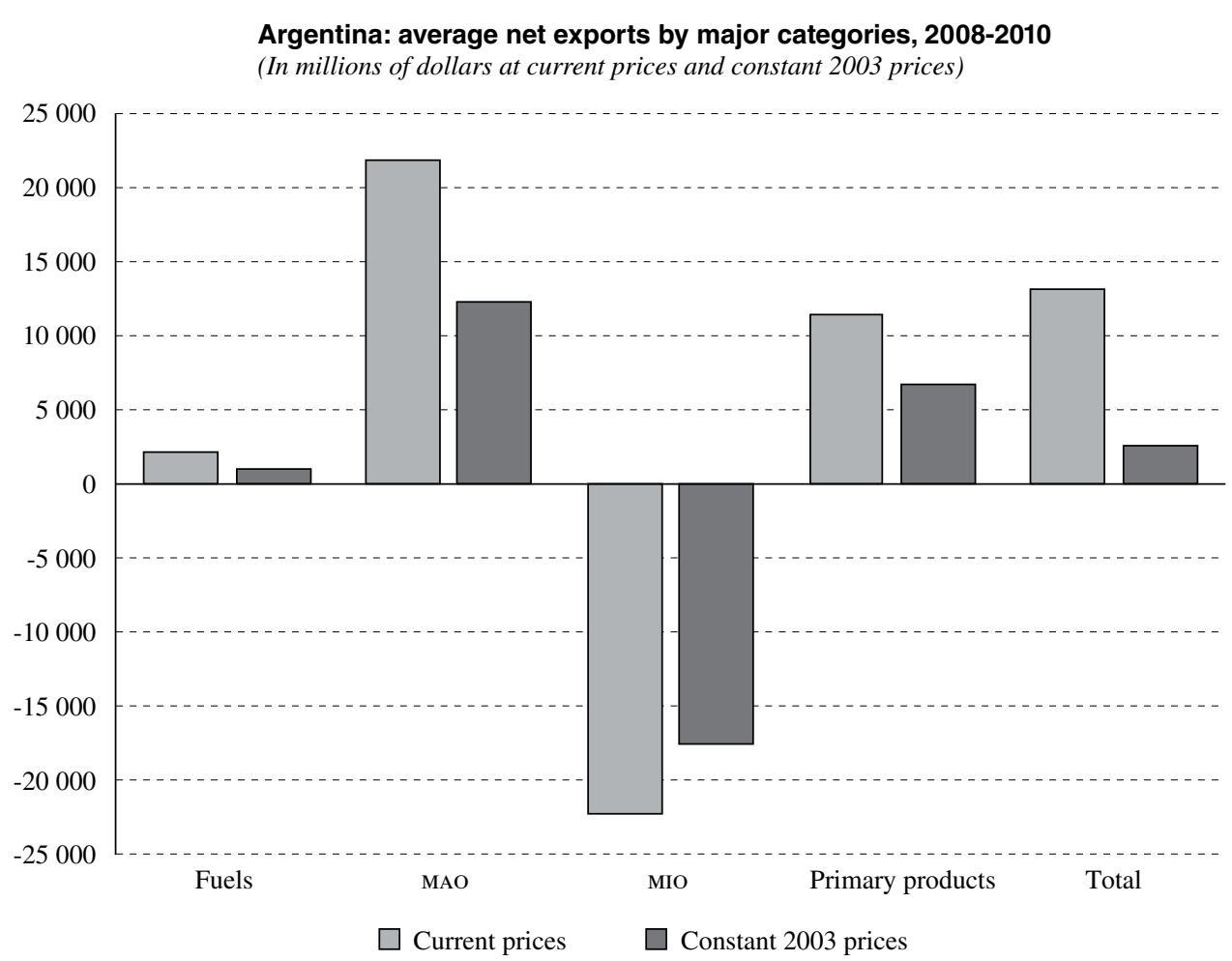

Source: prepared by the authors on the basis of National Institute of Statistics and Censuses (INDEC), United Nations Commodity Trade Statistics Database (COMTRADE) and National Foreign Trade Commission (CNCE).

MAO: manufactures of agricultural origin.

MIO: manufactures of industrial origin.

\section{Bilateral trade by major production categories and main trading partners}

Argentina's trade with its different trading partners has undergone profound shifts in recent years. Accordingly, this subsection will analyse that trade by major production category for the four most important trading areas: Brazil, China, the 27 member States of the European Union and the United States.

Primary products offer a clear example of the very marked shift in trade destinations away from more traditional markets such as Brazil and the European Union towards China. The evolution of the country's trade with each of these destinations is shown in figure 5.

It can be seen that there was a decisive shift away from Europe as a destination for soybean exports, and towards China. ${ }^{7}$ However, Argentina's trade in primary products with the European Union has remained at high levels because of strong growth in exports of fish (45\% of primary product exports by value) and maize (25\%). Meanwhile, there has been a marked slowdown in wheat exports to Brazil, which grew at an average annual rate of $2 \%$ during 1998-2009.

The situation is different in the case of MAO, where the main development has clearly been the growth of trade with the European Union, which still far outstrips that with the other selected partners (see figure 6). This performance is due to large exports of soybean milling by-products (soy pellets) used for animal feed, as these accounted for $54 \%$ of MAO exports to the European Union in 2007-2009.

7 During 1998-2009, exports of this type to China grew by a remarkable $29.5 \%$ a year, while exports to the European Union fell by $19 \%$. 
FIGURE 5

Argentina: primary product trade performance by country, 1998-2010

(Absolute value index) $^{\text {a }}$

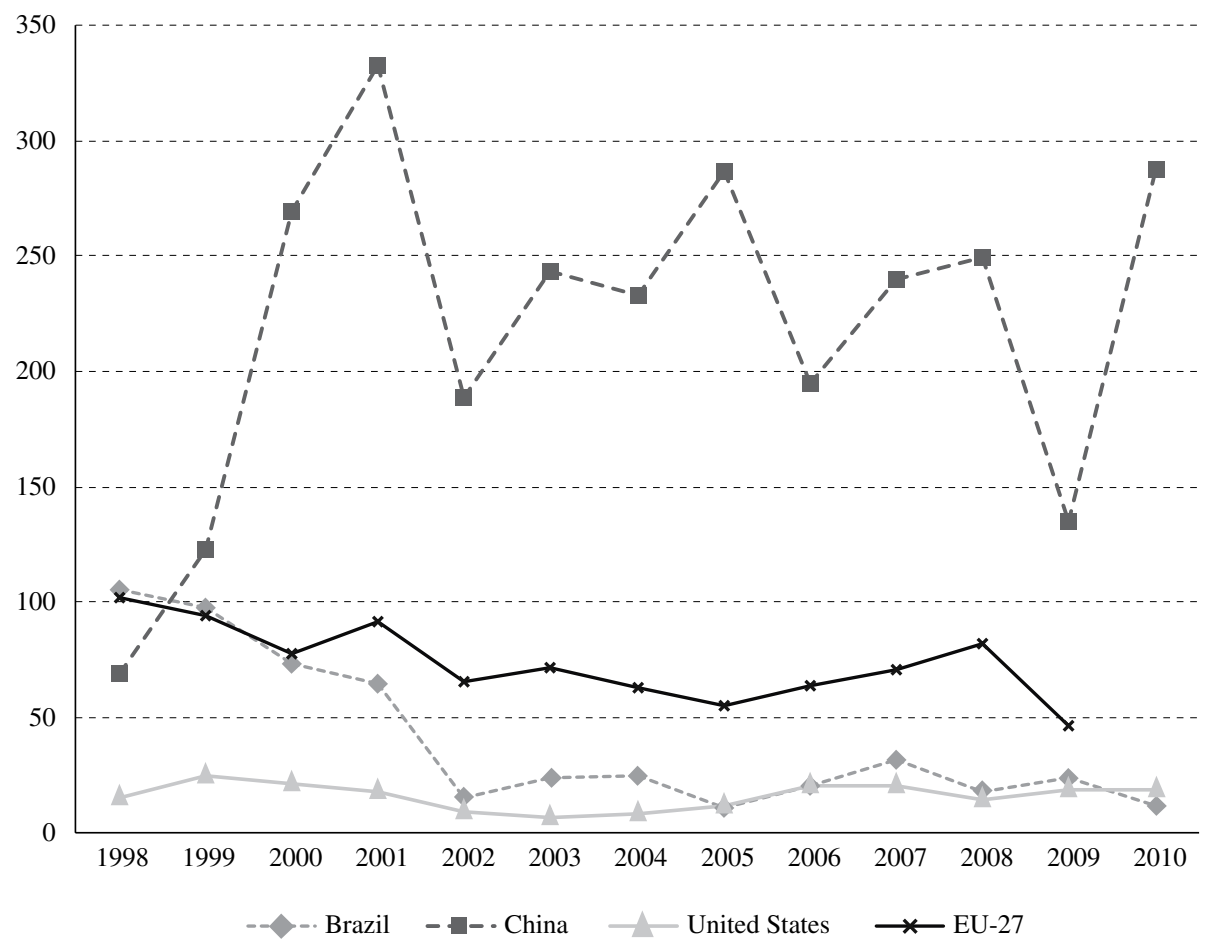

Source: prepared by the authors on the basis of National Institute of Statistics and Censuses (INDEC), United Nations Commodity Trade Statistics Database (COMTRADE) and National Foreign Trade Commission (CNCE).

a Figures calculated from the equations described in section IV.

Meanwhile, MAO trade with China also grew, although it was more unstable and largely confined to a single product of the soy chain: exports of soy oil grew by an average of $31 \%$ a year over the whole decade (despite a sharp drop in 2010) and represented $81 \%$ of MAO exports to that destination in 2007-2009. ${ }^{8}$ The large share of the soy complex in MAO exports and the dependence on the European Union and Chinese markets explain why the MAO trade balance was so concentrated.

As for the relationship with Brazil, MAO exports were never large, owing to that country's strategy of developing a strong food industry of its own. They fell sharply around 2003, owing to a large drop in powdered milk exports, before recovering on the back of wheat flour and malt exports, although without regaining the levels of the previous decade.

8 Soybeans outweigh oil in exports to China, however, which explains why commodities performed better than MAO in exports to that destination.
In the case of MIO, the country's relationships with its different trading partners altered substantially in the context of a quite negative trade performance. Trade with Brazil deteriorated sharply until the mid-2000s before beginning to recover, although without approaching earlier levels. Imports were dominated by automobiles and tractors ( $24 \%$ of imports), vehicle parts (10\%) and fixed-line and mobile telephones and other data transmission devices (6\%), a category in which imports from Brazil grew strongly once economic recovery began in Argentina. On the export side, automotive exports grew strongly in the last five years (55\% a year on average), with the result that their share of MIO exports to Brazil tripled, a development that largely explains the improvement in MIO trade to that destination noted earlier. However, this export growth was offset by a declining trade performance in the vehicle parts subsector, so that the net sectoral result is still a deficit for Argentina. 
FIGURE 6

Argentina: MAO trade performance by country, 1998-2010

(Absolute value index)*

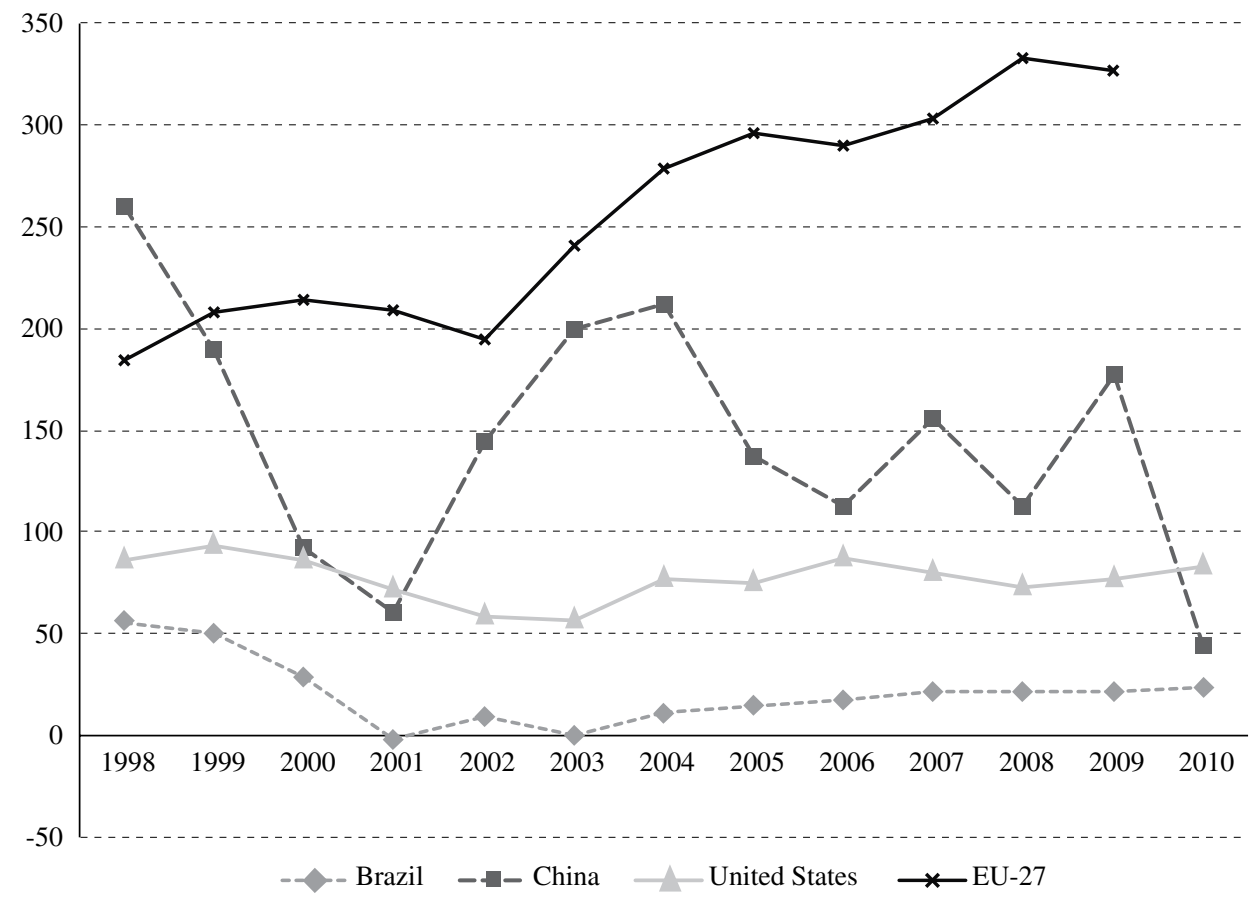

Source: prepared by the authors on the basis of National Institute of Statistics and Censuses (INDEC), United Nations Commodity Trade Statistics Database (COMTRADE) and National Foreign Trade Commission (CNCE).

* Figures calculated from the equations described in section IV. MAO: manufactures of agricultural origin.

The basic chemicals and special-purpose machinery sectors have also experienced a clear improvement in their trade with Brazil. However, special-purpose machinery remains an important component of the MIO deficit with Brazil, accounting for $9 \%$ of it, which is practically the same share as in the late 1990s.

Since 2003 there has been a sharp deterioration in the MIO trade balance with China, owing to rising imports of capital goods, machinery and electrical products and of inorganic chemical products, which account between them for some $60 \%$ of imports from that country by value. At the same time, there were improvements in the performance of the country's trade with the United States and the European Union (see figure 7), economies that have been displaced as suppliers of some industrial goods by China (capital goods and machinery and electrical appliances) and by Brazil (fixed-line and mobile telephones and vehicle parts). 
FIGURE 7

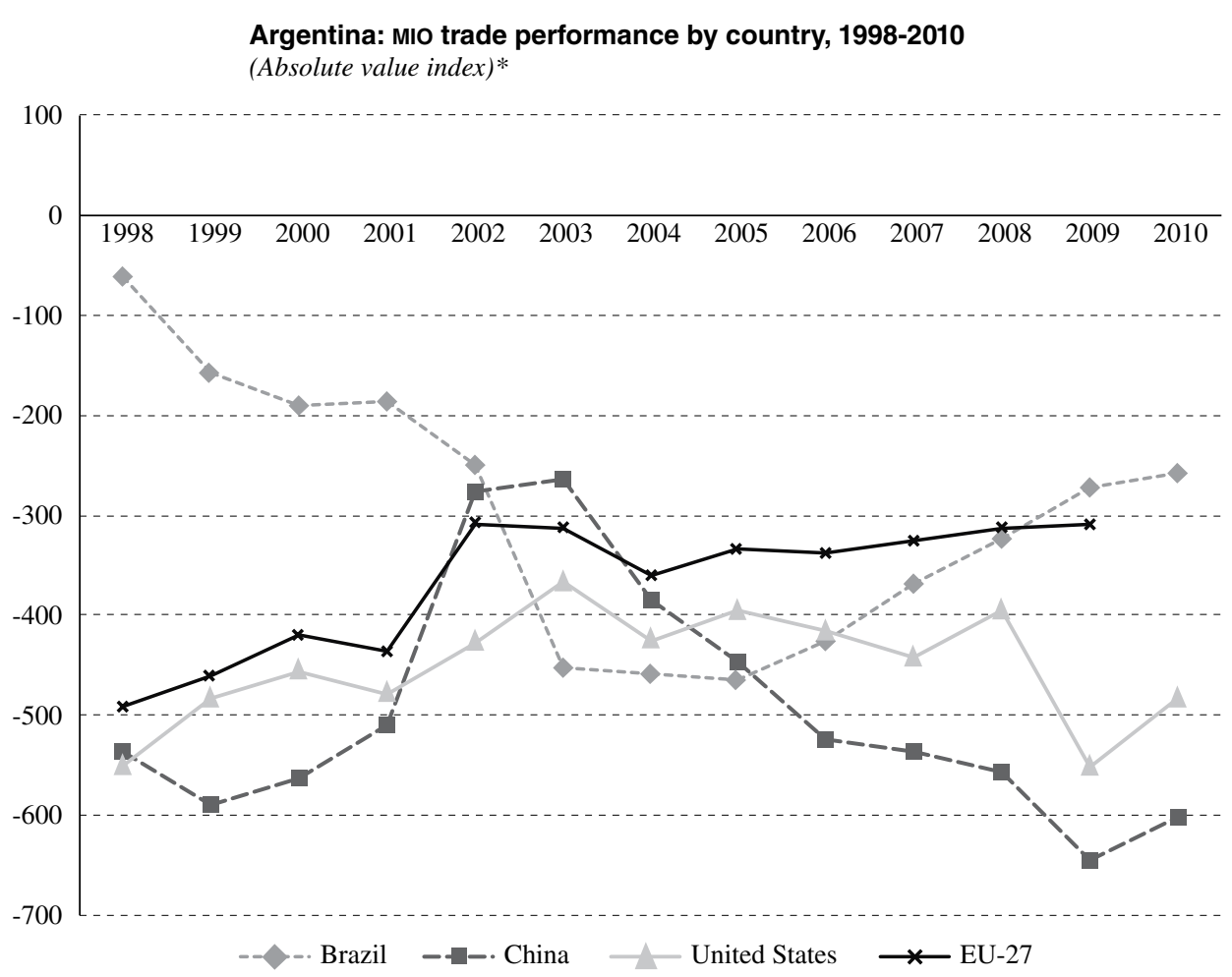

Source: prepared by the authors on the basis of National Institute of Statistics and Censuses (INDEC), United Nations Commodity Trade Statistics Database (COMTRADE) and National Foreign Trade Commission (CNCE).

* Figures calculated from the equations described in section IV. MIO: manufactures of industrial origin.

\section{Analysis of revealed comparative advantage (RCA) within the MIO category}

The performance of the main MIO sectors has been taking on a fundamental role in Argentina's foreign trade in relation to the overall average. Technological dependency remains high, as shown by the close link between activity levels and industrial imports of intermediate and capital goods. Although MIO exports grew strongly over the decade, the MIO trade deficit also increased as imports rose by even more, whence the importance of assessing developments in the main sectors in order to identify the principal changes undergone by these within the overall MIO category.

To do this, an MIO revealed comparative advantage index (RCAMIO) has been prepared for this study. It is an index of RCA within the MIO category, so that the evolution of each sector can be considered in relation to the average for this universe (see subsection 1(c) of section IV). This reworking of the data makes it possible to grasp changes within the MIO category and 
abstract these from the powerful influence of the primary products and MAO sectors on the levels and evolution of the RCA of MIO.

Using this methodology, the present section will analyse 16 sectors chosen for their large foreign trade shares or for their dynamism. These sectors account for $89 \%$ of MIO exports and $76 \%$ of imports, in contrast to their $45 \%$ share of the category's gross value added (GVA), which shows how strongly they interact with foreign trade by comparison with their share of local production. The following categorization is used to analyse this sectoral behaviour:

- Sectors with revealed comparative advantage (RCA) within the universe of manufactures of industrial origin (MIO).
- Sectors with weak revealed comparative disadvantage (RCD) within the MIO universe.

- Sectors with strong RCD within the MIO universe.

\section{Sectors with RCA within the MIO universe}

These sectors are the best positioned as contributors to the trade balance in the MIO category, as reflected in their $\mathrm{RCA}_{\mathrm{MIO}}$ index values in excess of zero 9 (see figure 8). On the whole, they do not present very significant levels of

9 Although some sectors present negative trade balances (automobiles and chemicals), their trade performance is clearly better than the MIO average, and this is reflected in positive $\mathrm{RCA}_{\mathrm{MIO}}$ index values within that universe.

FIGURE 8

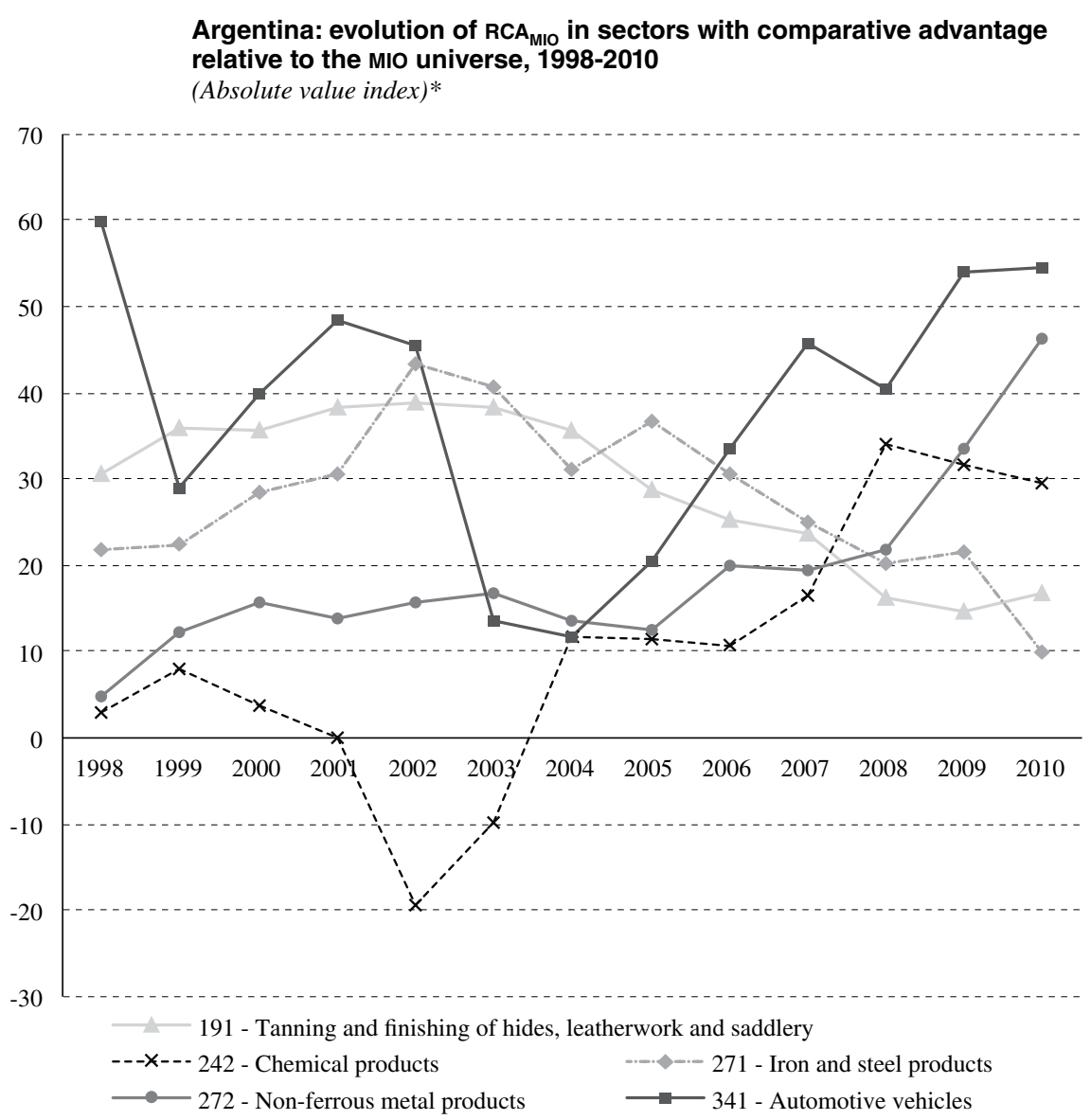

Source: prepared by the authors on the basis of National Institute of Statistics and Censuses (INDEC), United Nations Commodity Trade Statistics Database (COMTRADE) and National Foreign Trade Commission (CNCE).

* Figures calculated from the equations described in section IV. MIO: manufactures of industrial origin.

$\mathrm{RCA}_{\mathrm{MIO}}$ : index of revealed comparative advantage for MIO. 
import penetration in the local market (below $40 \%$, except in the case of automobiles), and their trade balances have improved (see table A.1 of annex I).

The automotive sector showed a striking jump in exports in the last five-year period (average annual growth of $21.8 \%$ ), bringing its trade into virtual balance. When vehicle components are added in, however, the trade of the sector as a whole remains in deficit (see section $\mathrm{V}$, subsection 2). It is important to note that the market for both spares and finished vehicles depends heavily on the globalizing strategies of multinational firms, ${ }^{10}$ which include a regional division of labour for inputs and products. Brazil is thus a very important destination, currently accounting for $81 \%$ of automotive vehicle sales.

The non-ferrous metals products sector is bound up with the performance of mining and its strong growth in the last five years, particularly for gold and aluminium. Unprocessed gold currently represents $89 \%$ of the trade surplus in this category and accounts for the sector's shift from deficit in the late 1990s to a surplus of US\$2.247 billion now. Primary aluminium is associated with the packaging industry, transport and construction, and behaved very dynamically, gaining comparative advantage and market share in a growing international market.

Within the chemical products sector, two subsectors clearly dominate. Biodiesel is a product that has benefited from the export tax differential with soy oil (its main input). ${ }^{11}$ External market conditions also turned favourable for this product when minimum biofuel thresholds were set in the European Union and the subsidy for the mixture of diesel and biodiesel was established in the United States in 2005.

The pharmaceutical sector has held its position as the country's best-developed high-technology sector, accounting for about $4.5 \%$ of total industrial gross output value (GVA). A particular feature of the sector in Argentina as compared to other Latin American countries is the predominance of locally-owned companies as suppliers to the domestic market. During the post-convertibility period, the sector performed very dynamically both domestically and abroad, with exports growing by $15 \%$ a year in the last five-year period. However, local

\footnotetext{
10 In fact, a study by the National Institute of Industrial Technology (INTI) (Queipo, 2008) argues that the country has the potential for growth in the supply of vehicle spares and electronic components, but this is restricted by the globalizing strategies referred to, implemented by original equipment makers to supply themselves from abroad.

11 Effective protection for the production of biodiesel from soy oil averaged 57.4\% in 2008-2010. See Bekerman and Dulcich (2012) for further details.
}

production did not rise quickly enough to cover domestic demand growth, so that import penetration in apparent consumption and the sector's trade deficit increased. Its main competitive weakness lies in the production of active ingredients, which are almost entirely bought in from abroad and account for a third of its imports. Subsidiaries of multinationals have a strong tendency to import, as locally-owned firms, by contrast, have a trade surplus (see CILFA, 2008). Here it should be pointed out that a group of smaller local firms have grown significantly in recent years by investing in technology and scaling up, which has enabled them to introduce their products into the wider Latin American market (CEP, 2009).

The strong external competitiveness of iron and steel products is mainly accounted for by the subsector of seamless tubes for oil and gas pipelines, whose share of the sector's exports by value rose from $33 \%$ to $51 \%$ in the past decade. It is interesting to note that the sector's export competitiveness, so heavily dominated by these seamless tubes for oil and gas extraction, is due to a single firm, Siderca, which has positioned itself as the world's leading supplier of seamless tubes and exported almost $70 \%$ of its output in the last five-year period. As a result, Argentina is now positioned as a major global supplier of seamless tubes, ranking fourth in international trade in 2005-2009 with $6.5 \%$ of this market, after China (20\% of the market), Japan (15.5\%) and Italy (6.9\%), which places it above even countries with a strong tradition in the iron and steel sector such as Germany (6.4\%) and the United States $(5.7 \%) .{ }^{12}$

\section{Sectors with weak revealed comparative disadvantage within the Mıo universe}

This group includes sectors with very diverse behaviour and, in some cases, higher levels of volatility than the earlier groups. This volatility is particular in evidence in two sectors: parts and accessories for the automotive industry, and manufactured fibres (see figure 9).

Parts and accessories for the automotive industry represent $10 \%$ of the MIO deficit and $90 \%$ of that of the automotive chain. Although exports increased rapidly over the decade (by $9.6 \%$ annually), comparative advantage was eroded, with imports rising strongly (an annual average of $17.3 \%$ in the last five-year period). At the same time, both the parts and accessories sector and the final vehicles sector have seen strong growth in imports over apparent consumption (see table A.1 in annex I), something that reflects growing production

12 United Nations Commodity Trade Statistics Database (COMTRADE). 


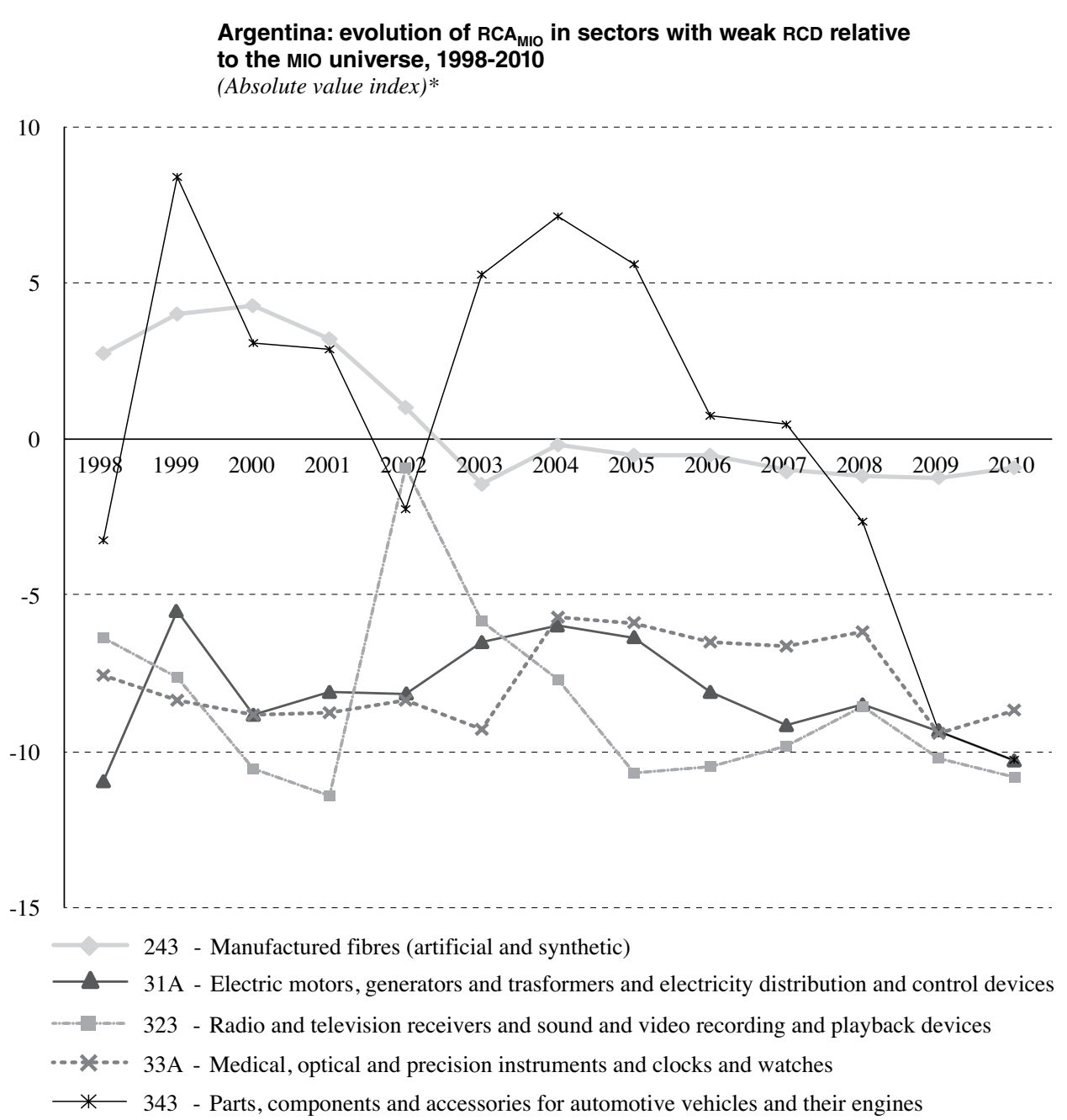

Source: prepared by the authors on the basis of National Institute of Statistics and Censuses (INDEC), United Nations Commodity Trade Statistics Database (COMTRADE) and National Foreign Trade Commission (CNCE).

* Figures calculated from the equations described in section IV.

$\mathrm{RCA}_{\mathrm{MIO}}$ : index of revealed comparative advantage for MIO.

RCD: revealed comparative disadvantage.

complementarity at the regional level as a result of the strategies of the multinationals present in Brazil and Argentina. As has already been pointed out, the trade deficit in the final vehicles sector did not fall by enough to offset the rising negative balance for parts and components.

The radios, stereos, televisions and recording devices sector also experienced a very substantial jump in imports over apparent consumption, to over $70 \%$ (see table A.1 in annex I), as well as a decline in exports. The electronics complex recorded considerable growth in physical output during the post-convertibility period, aided by exchange-rate protection and the Tierra del Fuego industrial promotion regime. However, it was not able to keep pace with rising demand or generate "backwards" productive linkages in the chain, a failing that was particularly acute in more technologically sophisticated segments. Consumer electronics, and the manufacture of radio and television receivers in particular, displayed great dynamism in terms of sales but a low degree of national integration based on imported components. Thus, the sector's recovery and growth in the post-convertibility 
period was accompanied by an even larger rise in its trade deficit (see table A.1 in annex I). ${ }^{13}$

The medical, optical and precision instruments and clocks and watches sector was practically dismantled during the convertibility period, suffering a steep drop in production between 1991 and 2002. Nonetheless, it has shown great dynamism in the domestic market during the post-convertibility period, increasing its share of industrial employment and showing signs of import substitution. However, its $\mathrm{RCA}_{\mathrm{MIO}}$ has been very volatile, perhaps because exports to new destinations (such as the Bolivarian Republic of Venezuela) have been sporadic, while Brazil has continued to be the main import partner. In any event, its ratio of imports to apparent consumption has remained high at over $70 \%$, while its trade deficit grew over the last five-year period (see table A.1 in annex I).

\section{Sectors with the greatest revealed comparative disadvantage within the MıO universe}

The sectors evincing the greatest revealed comparative disadvantage in relation to the MIO universe are shown in figure 10. They are in the areas of capital goods (general-purpose and special-purpose machinery and office and computing machinery) and industrial inputs (basic chemicals). Also in this category is the tubes, valves and radio and television transmitters and telephony devices sector, which comprises both inputs and final consumption goods, especially mobile telephones, which are very important in the sector's trade.

A more thorough examination of the specific sectors in this category shows that the level of import penetration for machinery is over $50 \%$, rising to as much as $90 \%$ in the case of computing machinery. Likewise, all sectors present growing trade deficits that reveal a continuing heavy dependence on foreign suppliers to provide the inputs and capital goods domestic economic activity requires (see table A.1 in annex I).

The machinery category includes sectors that require continuous innovation because they are subject to rapid obsolescence. Imports of general-purpose machinery (accounting for $10 \%$ of the MIO trade deficit) are highly diversified. Within the different subsectors, the largest net imports between 2008 and 2010 were of pumps and

13 The best-positioned subsector in terms of exports is the car stereo industry, which accounts for $79 \%$ of the sector's modest exports, while televisions and monitors accounted for 33\% of imports between 2008 and 2010. air compressors, followed by air conditioning equipment and centrifuges. Meanwhile, water turbines were the only sector with a positive trade balance. Two of the most dynamic subsectors are machines for treating substances by means of temperature changes (heaters, pasteurizers, dryers, sterilizers, coolers and so on) and lifting, loading, unloading and handling machines (lifts, conveyors, escalators and so on); net imports in these subsectors dropped by $40 \%$ over the decade, and between them they currently account for $10 \%$ of sectoral exports by value.

Special-purpose machinery, although also under a strong comparative disadvantage (see figure 10), has recovered somewhat since 2007. This situation was driven by two agricultural machinery subsectors: harvesters (with 30\% average annual export growth in the last five-year period) and seed drills and ploughs (31.4\%). The combination of a competitive exchange rate and the primary products price boom created new supply and demand conditions favourable to these subsectors during the post-convertibility period. In the agricultural tractors segment, on the other hand, the loss of production capacity during the convertibility crisis prevented local producers from responding to demand from farmers, and this was covered by imports, particularly from Brazil.

The structural disadvantage of computing and data processing machinery eased slightly from 2008 . Although this is a sector in which import penetration is almost complete ( $90 \%$ of apparent consumption), the size of its trade deficit within the group of MIO products has fallen from $12 \%$ in the aftermath of the crisis to $5 \%$ now. However, a sectoral study by the National Institute of Industrial Technology (INTI) reports that Argentina is unlikely to be able to increase its value added in this industry in the medium run or penetrate the more dynamic segments of the international market, such as computer hardware and telecommunications (Queipo, 2008).

Basic chemicals are one of the sectors showing the greatest fluctuations over the period. In the late 2000s, there was a sharp rise in imports associated with growth in agriculture, as it was driven particularly by fertilizers and by various organic chemical products (which now account between them for $78 \%$ of the sector's deficit). In the last five-year period, exports from these two subsectors fell by an average of $10 \%$ a year, while import growth averaged $8 \%$ a year. However, there has been no substantial rise in imports as a share of apparent consumption, something that reveals a growing role for domestic producers in supplying the local market (see table A.1 of annex I). 
FIGURE 10

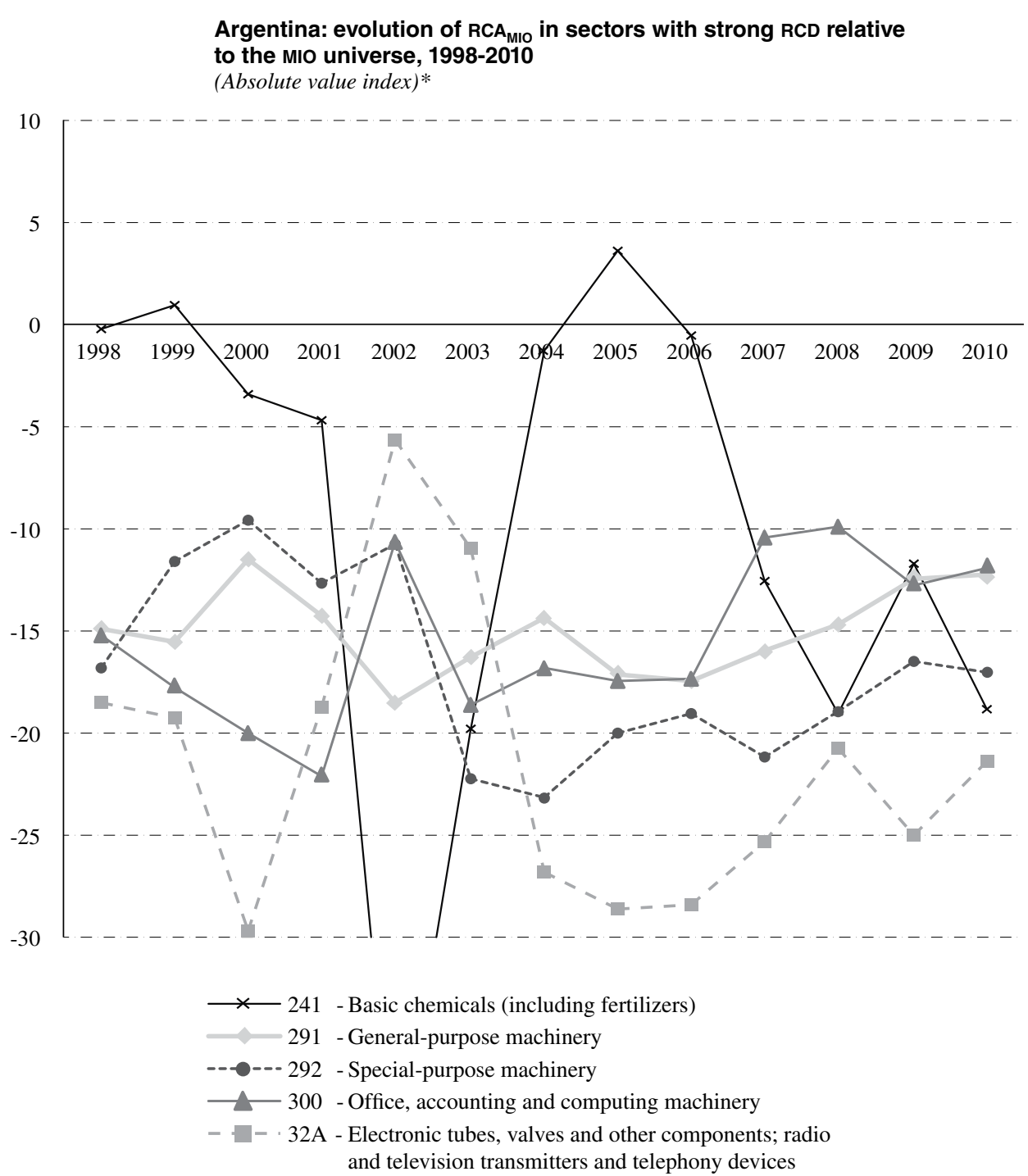

Source: prepared by the authors on the basis of National Institute of Statistics and Censuses (INDEC), United Nations Commodity Trade Statistics Database (COMTRADE) and National Foreign Trade Commission (CNCE).

* Figures calculated from the equations described in section IV. $\mathrm{RCA}_{\mathrm{MIO}}$ : index of revealed comparative advantage for MIO. RCD: revealed comparative disadvantage.

The electronic tubes, valves and other components and telephony devices sector shows the effects of the lack of historic continuity in technological development policies. Until the mid-1970s, a considerable variety of electronic parts and components, principally for televisions and audio equipment, were manufactured in Argentina to meet local demand. However, subsequent changes in tariff policy and the technological shift towards more and more complex components, combined with a lack of continuity in semiconductor manufacturing efforts in both the public sector (National Institute of Industrial Technology (INTI) and Armed Forces Institute for Scientific and Technical Research (CITEFA)) and the private sector (the electronics division of FATE) meant that local production almost ceased. The situation worsened during the 1990s, with import penetration in 
the domestic market rising from $38 \%$ in 1993 to $84 \%$ in 2001. This is now the sector with the greatest comparative disadvantage relative to MIo trade as a whole. Imports are heavily dominated by mobile phones, with domestic demand being almost completely met from abroad (see table A.1 of annex I). The sector's exports are virtually negligible, so that its growing trade deficit represents $10 \%$ of the MIO trade deficit.

\section{VI}

\section{Technology content, productivity and export performance in the different mIO sectors}

The evolution of RCA in the Argentine economy by technology content can be seen in figure $11 .{ }^{14}$ It can be clearly appreciated that comparative advantage is heavily concentrated in primary products (albeit decreasingly so in recent years), followed by agro-industrial products (which have offset this decline). This is because of the development, discussed above, of the earliest processing

14 The technology content of trade is classified in accordance with the correlation matrix of the National Foreign Trade Commission (CNCE). stages in the agrifood chain, such as the pressing of grains and oilseeds to produce oils, meals and animal feeds.

By contrast, all manufacturing sectors present comparative disadvantages, and these become more pronounced in high-technology manufactures. Where medium-technology links are concerned, comparative disadvantage is clearly greater in engineering-intensive industries than in process industries, which could reveal the continuing specialization bias of industry towards so-called industrial commodities.

FIGURE 11

Argentina: revealed comparative advantage (RCA) by technology content (Absolute value index)*

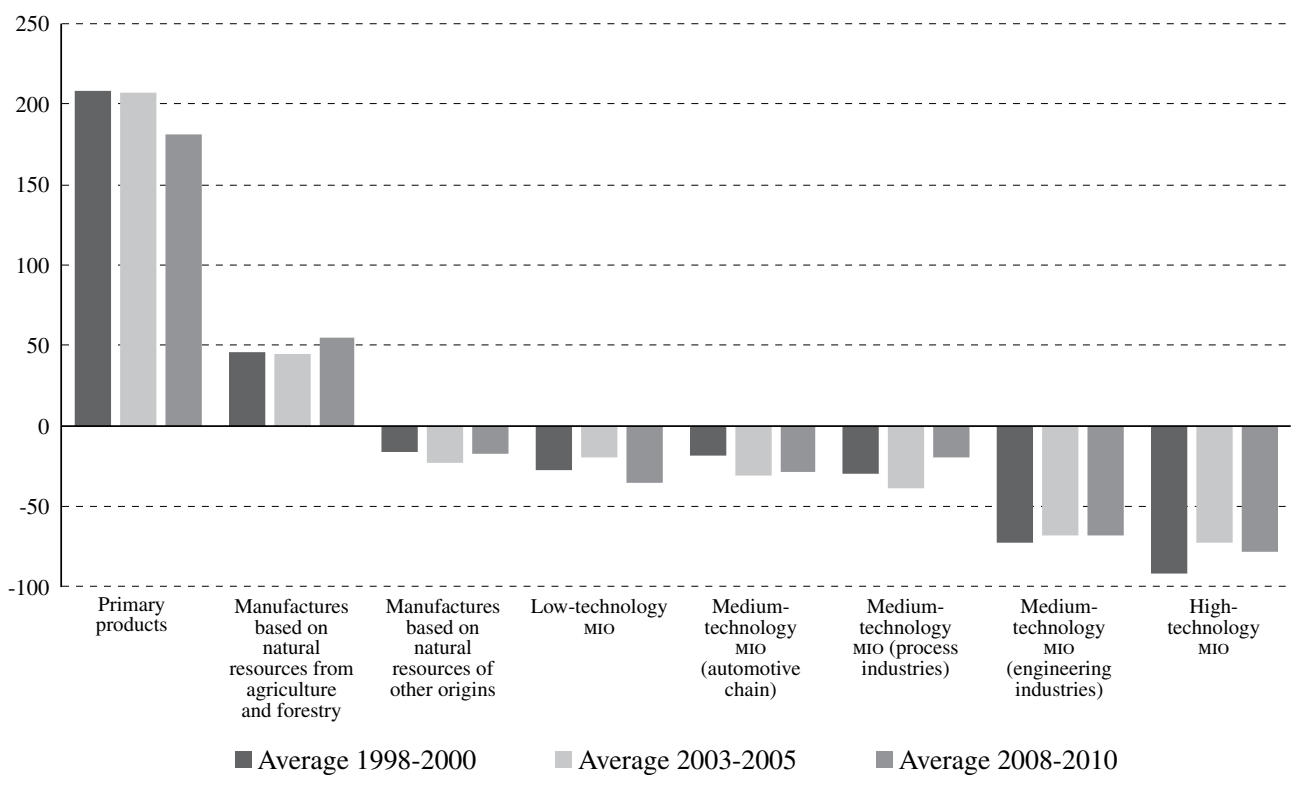

Source: prepared by the authors on the basis of National Institute of Statistics and Censuses (INDEC), United Nations Commodity Trade Statistics Database (COMTRADE) and National Foreign Trade Commission (CNCE).

* Figures calculated from the equations described in section IV. 
To classify the technology content of the main MIO sectors in accordance with the three categories given in section $\mathrm{V}$, table 1 presents national and international sectoral technology characterizations based on the classifications of the Production Research Centre (CEP) ${ }^{15}$

15 The CEP classification includes four subgroups for local research and development (R\&D) intensity. It is based on 2004 spending on local $R \& D$ as a proportion of turnover in the different sectors relative to the national average (see CEP, 2008). This sectoral expenditure may and the Organisation for Economic Cooperation and Development (OECD), ${ }^{16}$ respectively.

differ from average worldwide expenditure, however, and thus this classification may not pick up cases where a sector uses leading-edge technology from abroad, as may happen when it is dominated by multinational firms that invest in R\&D in developed countries and then transfer this knowledge to developing countries.

16 The sectoral technology content categorization is based on Hatzichronoglou (1997), as updated by OECD (2005) and Loschky (2008).

TABLE 1

Argentina: analysis of industrial RCA by technology content, 1998-2010

\begin{tabular}{|c|c|c|c|c|c|c|}
\hline $\begin{array}{l}\mathrm{RCA}_{\mathrm{MIO}} \\
\text { category }\end{array}$ & Sector & $\begin{array}{c}\text { GVA / } \\
\text { GOV 2003 } \\
\text { (percentages) }\end{array}$ & $\begin{array}{c}\text { CEP } \\
\text { technology } \\
\text { classification }\end{array}$ & $\begin{array}{c}\text { Argentine } \\
\text { R\&D } \\
\text { intensity } \\
\text { (percentages) }\end{array}$ & $\begin{array}{l}\text { OECD } \\
\text { classification }^{a}\end{array}$ & $\begin{array}{c}\text { Relationship } \\
\text { Argentina- } \\
\text { abroad } \\
\text { (CEP vs. } \\
\text { OECD) }\end{array}$ \\
\hline \multirow{5}{*}{$\begin{array}{l}\text { Revealed } \\
\text { comparative } \\
\text { advantage } \\
\text { (RCA) }\end{array}$} & $\begin{array}{l}191 \text { - Tanning and finishing of hides, leatherwork } \\
\text { and saddlery }\end{array}$ & 19.8 & LLT & 0.06 & LT & Same \\
\hline & 242 - Chemical products & 35.6 & HLT & 0.84 & $\mathrm{HT}$ b & Same \\
\hline & 271 - Iron and steel products & 41.8 & MLLT & 0.11 & MLT & Same \\
\hline & 272 - Non-ferrous metal products & 31.7 & MLLT & 0.24 & MLT & Same \\
\hline & 341 - Automotive vehicles & 16.5 & LLT & 0.08 & MHT & Different \\
\hline \multirow{4}{*}{$\begin{array}{l}\text { Weak revealed } \\
\text { comparative } \\
\text { disadvantage }\end{array}$} & 243 - Manufactured fibres (artificial and synthetic) & 35.0 & LLT & 0.00 & MHT & Different \\
\hline & $\begin{array}{l}\text { 31A - Electric motors, generators and transformers } \\
\text { and electricity distribution and control devices }\end{array}$ & 42.7 & MLLT $^{\mathrm{c}}$ & 0.22 & MHT & Different \\
\hline & $\begin{array}{l}323 \text { - Radio and television receivers and sound and } \\
\text { video recording and playback devices }\end{array}$ & 38.0 & MLLT & 0.19 & HT & Different \\
\hline & $\begin{array}{l}343 \text { - Parts, components and accessories for automotive } \\
\text { vehicles and their engines }\end{array}$ & 34.8 & HLT & 0.97 & MHT & Different \\
\hline \multirow{6}{*}{$\begin{array}{l}\text { Strong revealed } \\
\text { comparative } \\
\text { disadvantage }\end{array}$} & 241A - Basic chemicals (excluding fertilizers) & 31.1 & LLT & 0.08 & мнт & Different \\
\hline & 241B - Fertilizers and other agricultural chemical products & 60.8 & LLT & 0.08 & MHT & Different \\
\hline & 291 - General-purpose machinery & 40.9 & MHLT & 0.36 & MHT & Same \\
\hline & 292 - Special-purpose machinery & 41.0 & MHLT & 0.44 & MHT & Same \\
\hline & 300 - Office, accounting and computing machinery & 40.0 & HLT & 1.79 & HT & Same \\
\hline & $\begin{array}{l}\text { 32A - Electronic tubes, valves and other components, } \\
\text { radio and television transmitters and telephony devices }\end{array}$ & 32.1 & HLT ${ }^{\text {e }}$ & 0.59 & HT & Same \\
\hline \multicolumn{2}{|c|}{ Average for manufactures of industrial origin (MIO) } & 34.2 & & & & \\
\hline
\end{tabular}

Source: prepared by the authors on the basis of National Institute of Statistics and Censuses (INDEC) and Production Research Centre (CEP).

Note: gross value added (GVA) / gross output value (GOV) of 243, constructed as an average of 241 and 242 (prepared by the authors on the basis of the sources indicated).

Nomenclature as per Production Research Centre (CEP) classification: LLT = low local technology, MLLT = medium-low local technology, MHLT = medium-high local technology, HLT $=$ high local technology.

Nomenclature as per the Organisation for Economic Co-operation and Development (OECD) classification: $\mathrm{LT}=$ low technology, MLT $=$ mediumlow technology, MHT = medium-high technology, HT = high technology.

RCA: revealed comparative advantage.

$\mathrm{RCA}_{\mathrm{MIO}}$ : revealed comparative advantage of MIO.

a According to Loschky (2008).

b R\&D intensity for chemicals (242) as given by the oECD covers pharmaceuticals (subsector 2423, part of 242). Source: Production Research Centre (CEP).

c Classified by the average Argentine R\&D intensity of sectors 311 and 312, which make up sector 31A; and using the CEP methodology (own calculations).

d Classified by the average Argentine R\&D intensity of sectors 331 and 332, which make up sector 33A; and using the cEP methodology (own calculations).

e Classified by the average Argentine R\&D intensity of sectors 321 and 322, which make up sector 32A; and using the CEP methodology (own calculations). 
It can be seen from table 1 that within the first category, showing the sectors that are best placed within the MIO group, just one, chemicals, is counted as a hightechnology sector in both classifications. In other words, sectors with positive $\mathrm{RCA}_{\mathrm{MIO}}$ are usually medium- or low-technology ones.

The automotive vehicles sector is classed differently by the OECD and CEP technology classifications. This may be because this sector is dominated by multinationals, whose operating methods may mean that they do not develop technology locally in certain production hubs. This may be associated with the fact that the ratio between added value and gross output value (GOV) is substantially lower than in the other sectors, owing to the large share of parts that are imported, as already discussed.
These differences in technology classification come up again in other sectors where multinational firms are heavily involved, or where imported technology is used. This situation is found in all sectors that have low levels of comparative disadvantage within the MIO universe, with the exception of medical instruments.

Machinery and electronic tubes, valves and other components, which, as already pointed out, are at a strong comparative disadvantage within the MIO universe and plainly import-dependent, are placed by both classifications in the medium- and high-technology categories.

Where variations in productivity are concerned, table 2 reveals that the sectors with the strongest $\mathrm{RCA}_{\mathrm{MIO}}$ include those where productivity rose by least during the decade (with the exception of non-ferrous metal

TABLE 2

Argentina: analysis of industrial RCA by evolution of productivity, and productivity level relative to the United States, 2005

\begin{tabular}{|c|c|c|c|c|}
\hline \multirow{2}{*}{$\begin{array}{l}\mathrm{RCA}_{\mathrm{MIO}} \\
\text { category }\end{array}$} & \multirow{2}{*}{ Sector } & \multicolumn{2}{|c|}{$\begin{array}{l}\text { Change in productivity } \\
(1998-2000 \text { and } 2008-2010)\end{array}$} & \multirow{2}{*}{$\begin{array}{l}\text { Labour } \\
\text { productivity } \\
\text { relative to the } \\
\text { United States } \\
\text { in } 2005^{\text {a }} \\
\text { (percentages) }\end{array}$} \\
\hline & & $\begin{array}{l}\text { Per worker } \\
\text { employed } \\
\text { (percentages) }\end{array}$ & $\begin{array}{l}\text { Per hour worked } \\
\text { (percentages) }\end{array}$ & \\
\hline \multirow{5}{*}{$\begin{array}{l}\text { Revealed } \\
\text { comparative } \\
\text { advantage } \\
\text { (RCA) }\end{array}$} & 191 - Tanning and finishing of hides, leatherwork and saddlery & 12.8 & 18.1 & 124.6 \\
\hline & 242 - Chemical products & 16.4 & 19.1 & $71.9^{b}$ \\
\hline & 271 - Iron and steel products & 39.8 & 32.1 & 80.7 \\
\hline & 272 - Non-ferrous metal products & 105.4 & 109.7 & 41.6 \\
\hline & 341 - Automotive vehicles & 44.0 & 31.9 & $61.0^{\mathrm{c}}$ \\
\hline \multirow{5}{*}{$\begin{array}{l}\text { Weak revealed } \\
\text { comparative } \\
\text { disadvantage }\end{array}$} & 243 - Manufactured fibres (artificial and synthetic) & -24.1 & -15.1 & $40.9^{\mathrm{d}}$ \\
\hline & $\begin{array}{l}\text { 31A - Electric motors, generators and transformers and electricity } \\
\text { distribution and control devices }\end{array}$ & 52.4 & 61.2 & $3.8^{\mathrm{e}}$ \\
\hline & playback devices & 78.8 & 74.2 & 14.3 \\
\hline & 33A - Medical, optical and precision instruments and clocks and watches & 52.4 & 55.8 & 9.0 \\
\hline & $\begin{array}{l}343 \text { - Parts, components and accessories for automotive vehicles and } \\
\text { their engines }\end{array}$ & 13.1 & 21.3 & $61.0^{\mathrm{c}}$ \\
\hline \multirow{6}{*}{$\begin{array}{l}\text { Strong } \\
\text { revealed } \\
\text { comparative } \\
\text { disadvantage }\end{array}$} & 241A - Basic chemicals (excluding fertilizers) & 33.7 & 33.1 & $71.9 \mathrm{~b}$ \\
\hline & 241B - Fertilizers and other agricultural chemicals & 87.7 & 89.7 & $71.9^{b}$ \\
\hline & 291 - General-purpose machinery & 56.3 & 61.6 & $20.5^{\mathrm{f}}$ \\
\hline & 292 - Special-purpose machinery & 40.3 & 46.7 & $20.5^{\mathrm{f}}$ \\
\hline & 300 - Office, accounting and computing machinery & -48.1 & -45.5 & $20.5^{\mathrm{f}}$ \\
\hline & $\begin{array}{l}\text { 32A - Electronic tubes, valves and other components, radio and } \\
\text { television transmitters and telephony devices }\end{array}$ & -45.0 & -43.0 & $3.8 \mathrm{e}$ \\
\hline \multicolumn{2}{|c|}{ Average for selected sectors } & 32.2 & 34.4 & 44.9 \\
\hline \multicolumn{2}{|c|}{ Industry average (includes manufactures of both agricultural and industrial origin) } & 35.8 & 41.1 & 36.9 \\
\hline
\end{tabular}

Source: prepared by the authors on the basis of Production Research Centre (CEP) and J. Katz and G. Bernat, "Creación de empresas, crecimiento en la productividad y cambio estructural como respuesta a una modificación en la política macroeconómica. Evidencia para la Argentina", Revista de Economía Política de Buenos Aires, year 5, vols. 9 and 10, Buenos Aires, University of Buenos Aires, 2011.

a As percentage of average output per worker employed (at 1985 prices).

b Corresponds to the aggregate sector "Chemicals".

c Corresponds to the aggregate sector "Transport equipment".

d Weighted average of the "Textiles" sector (66.7\%) and the "Plastic products" sector (33.3\%).

e Corresponds to the aggregate sector "Electronic equipment".

f Corresponds to the aggregate sector "Machinery and equipment". 
products), in contrast to the strong growth seen in MIO sectors with revealed comparative disadvantage, such as electric motors and generators, radio and television receivers, fertilizers and general-purpose machinery. However, sectors with $\mathrm{RCA}_{\mathrm{MIO}}$ are very close to the international frontier in terms of technical process, as their productivity differential with the United States is much smaller than the overall differential for industry, which is about $37 \%$. This suggests that these advantages are to be ascribed more to the small differential with the international frontier than to international demand growth, as might be the case with certain primary products and their derivatives. This proximity to the international frontier may help to explain why productivity growth has been lower there than in sectors with comparative disadvantage. The latter often present very low levels of productivity per worker employed by comparison with their United States counterparts, suggesting that these disadvantages may be due to the large productivity gap with the international frontier.

\section{VII}

\section{Summary and conclusions}

The pattern of international specialization in the Argentine economy has not changed greatly in the past decade as far as the major production categories are concerned. Primary products and MAO account for much of the country's external competitiveness and trade surplus. Within this context, however, there have been significant changes in the composition of primary products and MAO and in trade flows by origin and destination, as well as a sharp decline in the comparative advantage of fuels.

These shifts have largely been the result of strong growth in the relative prices of commodities, owing to rising demand from Asian countries. Without embarking upon a general equilibrium analysis, however, it can be said that the country has a trade surplus even when the favourable evolution of external relative prices is discounted, even though the past few years have been a time of strong growth in the Argentine economy.

MIO are still in a situation of comparative disadvantage, however, with a growing structural deficit, as the Argentine economy has not yet been able to weaken the strong link between activity levels and imports of certain types of machinery, inputs and parts and components. Nor has it been able to find satisfactory substitutes for imports in the face of strong demand for certain final goods, especially high-technology ones such as televisions and mobile phones.

Again, the composition of MIO exports displays strong growth in items that have benefited from favourable regimes, such as primary gold and aluminium and biodiesel. Also worthy of note is the automotive industry, which has benefited from a special regime under the rules of the Southern Common Market (MERCOSUR).
These sectors, along with seamless tubes for oil and gas, have provided the main underpinning for growth in MIO exports since the end of the convertibility regime.

Thus, the pattern of trade specialization in Argentina is still heavily concentrated in sectors associated with primary products and standardized industrial processes (this being true of both MAO and MIO), usually with limited differentiation of products and processes and often plainly dependent on foreign capital goods and components. It should be noted, however, that some high-technology industrial sectors, such as certain agricultural machinery subsectors, are beginning to develop external competitiveness.

Where destinations are concerned, changes in the origins of MIO imports and shifts in the export destinations for primary products and MAO have been essentially due to the emergence of China as a major player in the global economy. The growth of China as a buyer of commodities and foodstuffs and as a supplier of industrial goods is tending to push emerging economies towards specialization in the primary product sector. This may be accentuated over time, in view of the goals set in the country's latest five-year plan, which include the development of more technologically sophisticated industrial segments. It is important to note that the more prominent role of China and Brazil as new trading partners has displaced traditional partners, so that the long-standing concentration of Argentina's external trade in a few countries has persisted.

In the light of the theoretical considerations set out, it can be said that both the sustainability and the level of long-run growth may be affected if this trading 
pattern is maintained in the future and industry remains heavily dependent on imported capital goods and inputs. Likewise, the slower growth in the overall productivity of the economy implied by specialization in standardized sectors means a lesser potential for real wages to rise without affecting capital development and accumulation, something that may worsen distributive strains. Again, the heavy sectoral and regional concentration of the Argentine economy's external trade means that it is reliant on a few markets.

This context is creating major challenges, especially given the changes that are occurring in the production structure around the world. There is a need to promote export diversification based on the expansion of value added in existing industries and of strategic sectors that can play a leadership role, taking the MERCOSUR market as a first step in the fulfilment of this strategy. To meet these objectives it is necessary, first, to carry out macroeconomic management in a way that ensures the real exchange rate is conducive to productive development. Second, it is necessary to implement specific policies that alter the vector of free market prices determining "static efficiency" and thereby tend to favour export diversification. This requires a process of strategic collaboration between the public and private sectors to generate the information needed for the successful design and implementation of industrial policies. It also requires strong political authority to administer the conflicts of interests between different groups that may be created by the implementation of such policies. A supplementary challenge is to impose a system of reciprocity or rewards and punishments that encourages investment in non-traditional sectors but, as discussed by Rodrik (2005), that can also detect failing investments and generate the conditions for a system to capture revenues.

Some fundamental changes of course have been observable in recent years, and these should not be underestimated, but the main challenge now facing Argentina is much the same as it was two decades ago: "the need to develop a production structure that can improve its trade performance and generate more productive employment by reducing structural heterogeneity so that income distribution is improved and extreme poverty reduced" (Rosales, 1989). 
ANNEX I

TABLE A.1

Argentina: import penetration and trade balance in the MIO sectors considered

\begin{tabular}{|c|c|c|c|c|c|c|}
\hline \multirow{2}{*}{ Sector } & \multicolumn{3}{|c|}{$\begin{array}{l}\text { Imports/apparent consumption } \\
\text { (percentages) }\end{array}$} & \multicolumn{3}{|c|}{$\begin{array}{l}\text { Trade balance } \\
\text { (millions of dollars) }\end{array}$} \\
\hline & $\begin{array}{l}\text { Average } \\
1998-2000\end{array}$ & $\begin{array}{l}\text { Average } \\
2008-2010\end{array}$ & $\begin{array}{l}\text { Linear } \\
\text { change }\end{array}$ & $\begin{array}{l}\text { Average } \\
1998-2000\end{array}$ & $\begin{array}{l}\text { Average } \\
2008-2010\end{array}$ & $\begin{array}{l}\text { Linear } \\
\text { change }\end{array}$ \\
\hline $\begin{array}{l}191 \text { - Tanning and finishing of hides, leatherwork } \\
\text { and saddlery }\end{array}$ & 8.4 & 11.8 & 3.4 & 723 & 755 & 33 \\
\hline 241B - Fertilizers and other agricultural chemicals & 27.6 & 28.8 & 1.2 & -248 & -832 & -585 \\
\hline 242 - Chemical products & 16.9 & 26.7 & 9.8 & -1258 & -97 & 1161 \\
\hline 243 - Manufactured fibres (artificial and synthetic) & 26.9 & 51.7 & 24.8 & 15 & -147 & -162 \\
\hline 271 - Iron and steel products & 17.4 & 17.5 & 0.2 & 144 & 45 & -99 \\
\hline 272 - Non-ferrous metal products & 31.7 & 40.8 & 9.1 & 22 & 1384 & 1363 \\
\hline 291 - General-purpose machinery & 53.9 & 53.1 & -0.8 & -1577 & -2124 & -547 \\
\hline 300 - Office, accounting and computing machinery & 93.0 & 97.1 & 4.1 & -1167 & -1135 & 32 \\
\hline $\begin{array}{l}323 \text { - Radio and television receivers and sound and video } \\
\text { recording and playback devices }\end{array}$ & 41.4 & 70.6 & 29.2 & -553 & -1007 & -454 \\
\hline 341 - Automotive vehicles & 37.7 & 55.9 & 18.2 & -465 & -200 & 265 \\
\hline $\begin{array}{l}343 \text { - Parts, components and accessories for automotive } \\
\text { vehicles and their engines }\end{array}$ & 40.7 & 53.8 & 13.1 & -849 & -1874 & -1025 \\
\hline $\begin{array}{l}31 \mathrm{~A} \text { - Electric motors, generators and transformers and } \\
\text { electricity distribution and control devices }\end{array}$ & 60.8 & 64.2 & 3.4 & -693 & -1113 & -420 \\
\hline $\begin{array}{l}\text { 33A - Medical, optical and precision instruments and } \\
\text { clocks and watches }\end{array}$ & 67.1 & 71.4 & 4.3 & -659 & -967 & -308 \\
\hline $\begin{array}{l}32 \mathrm{~A} \text { - Electronic tubes, valves and other components and } \\
\text { radio and television transmitters and telephony devices }\end{array}$ & 79.2 & 97.8 & 18.6 & -1444 & -2184 & -740 \\
\hline
\end{tabular}

Source: prepared by the authors on the basis of National Institute of Statistics and Censuses (INDEC), United Nations Commodity Trade Statistics Database (COMTRADE) and National Foreign Trade Commission (CNCE).

MIO: manufactures of industrial origin. 
ANNEX II

Methodological aspects

\section{Databases and information sources}

The sectoral categorization and the information on exports as a share of sectoral gross output value and imports as a share of sectoral apparent consumption are taken from the 2010 sectoral records of the Production Research Centre (CEP). ${ }^{17}$

The external trade database covers Argentine external trade in 1998-2009 as per the six-digit MERCOSUR Common Nomenclature (NCM), 2002 harmonized system (Source: INDEC and COMTRADE).

This database was converted to the nomenclature of the International Standard Industrial Classification of All Economic Activities (ISIC), Revision 3.1, produced by the United Nations; and to the major categories, economic use and technology content using the correlation matrix of the National Foreign Trade Commission (CNCE) from June 2003.

17 Available at [online] http://www.cep.gov.ar/descargas_new/ estadisticas/sectores/fichas_sectoriales_2010.xls.
The conversion of current external trade flows to constant 2003 prices was carried out using the index of import prices by economic use, base $1993=100$, and the index of export prices by major categories, base $1993=100$ (Source: INDEC in both cases). These indices were weighted by the share of the economic use or major category in each year, employing the CNCE trade databases and correlation matrix already referred to. The macroeconomic data for GDP and composition of aggregate demand are also from INDEC.

\section{Sectoral categorization}

The MIO categorization took 32 sectors from the SITC Rev. 3.1 three-digit classification and 10 MIO sectors aggregated by categories by CEP for its sectoral records. Sixteen of these sectors were chosen for the analysis, 11 from the SITC Rev 3.1 classification and 5 of those prepared by CEP, in view of their preponderance in the level or evolution of trade and industrial production.

Bibliography

Agosin, M. (2009), "Export diversification and growth in emerging economies", CEPAL Review, No. 97 (LC/G.2400-P), Santiago, Chile, April.

Appleyard, D. and A. Field (1997), International Economics, New York, McGraw-Hill Professional Publishing.

Bekerman, M. and D. Cerdeiro (2007), "Integración, crisis y patrón de especialización de la economía argentina (1994 - 2005)", Documento de Trabajo, No. 16, Buenos Aires, Center of Studies of the Economic Structure (CENES).

Bekerman, M. and F. Dulcich (2012), "Transformaciones recientes en el patrón de especialización de la economía argentina", Documento de Trabajo, No. 21, Buenos Aires, Center of Studies of the Economic Structure (CENES).

Bekerman, M. and P. Sirlin (1999), "Patrón de especialización y desarrollo de la economía argentina", Documento de Trabajo, No. 4, Buenos Aires, Center of Studies of the Economic Structure (CENES).

CEP (Production Research Centre) (2009), "La industria farmacéutica en la Argentina", Buenos Aires, January [online] http:// www.cep.gov.ar/descargas_new/panorama_sector_industria/ presentaciones_sectoriales/farmacia.pdf. (2008), "Contenido tecnológico de las exportaciones argentinas 1996-2007. Tendencias de upgrading intersectorial" [online] www.cep.gov.ar.

CILFA (Cámara Industrial de Laboratorios Farmacéuticos Argentinos) (2008), Trayectorias sectoriales en la industria de la postconvertibilidad. En busca de indicios de cambio estructural, Buenos Aires.

Hatzichronoglou, T. (1997), "Revision of the high-technology sector and product classification", Science, Technology and Industry
Working Papers, No. 1997/2, Paris, Organisation for Economic Cooperation and Development (OECD).

Hausmann, R. and D. Rodrik (2003), "Economic development as self-discovery”, Journal of Development Economics, vol. 72, No. 2, Amsterdam, Elsevier.

Katz, J. and G. Bernat (2011), "Creación de empresas, crecimiento en la productividad y cambio estructural como respuesta a una modificación en la política macroeconómica. Evidencia para la Argentina", Revista de Economía Política de Buenos Aires, year 5, vols. No. 9 and 10, Buenos Aires, University of Buenos Aires.

Loschky, A. (2008), "Reviewing the nomenclature for high-technology trade. The sectoral approach" (STD/SES/WPTGS(2008)9), Paris, Organisation for Economic Cooperation and Development (OECD), September.

Miotti, L., C. Quenan and C. Winograd (1998), "Spécialisation internationale et intégration régionale. L'Argentine et le MERCOSUR", Économie internationale, No. 74, Paris, CEPII.

OECD (Organisation for Economic Cooperation and Development) (2005), OECD Handbook on Economic Globalisation Indicators, Paris.

Queipo, G. (2008), "Industria electrónica en Argentina: Situación actual y perspectivas", Buenos Aires, National Institute of Industrial Technology.

Rodrik, D. (2005), "Policies for economic diversification", CEPAL Review, No. 87 (LC/G.2287-P), Santiago, Chile, December.

Rosales, O. (1989), "Marco externo, estrategias de desarrollo y ajuste estructural", Desarrollo Económico, vol. 29, No. 113, April-June, Buenos Aires, Institute of Economic and Social Development.

Wade, R. (1989), "What can economics learn from East Asian success?", Annals of the American Academy of Political and Social Science, vol. 505, Thousand Oaks, Sage Publications. 